\title{
Novel multivalent design of a monoclonal antibody improves binding strength to soluble aggregates of amyloid beta
}

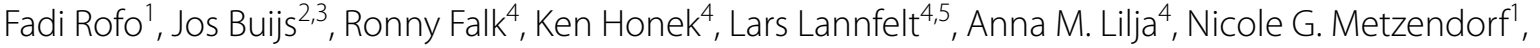

Tobias Gustavsson ${ }^{5}$, Dag Sehlin ${ }^{5}$, Linda Söderberg ${ }^{4}$ and Greta Hultqvist ${ }^{*}$ (1)

\begin{abstract}
Background: Amyloid- $\beta(A \beta)$ immunotherapy is a promising therapeutic strategy in the fight against Alzheimer's disease (AD). A number of monoclonal antibodies have entered clinical trials for AD. Some of them have failed due to the lack of efficacy or side-effects, two antibodies are currently in phase 3 , and one has been approved by FDA. The soluble intermediate aggregated species of $A \beta$, termed oligomers and protofibrils, are believed to be key pathogenic forms, responsible for synaptic and neuronal degeneration in AD. Therefore, antibodies that can strongly and selectively bind to these soluble intermediate aggregates are of great diagnostic and therapeutic interest.
\end{abstract}

Methods: We designed and recombinantly produced a hexavalent antibody based on mAb158, an A $\beta$ protofibrilselective antibody. The humanized version of mAb158, lecanemab (BAN2401), is currently in phase 3 clinical trials for the treatment of $\mathrm{AD}$. The new designs involved recombinantly fusing single-chain fragment variables to the $\mathrm{N}$-terminal ends of mAb158 antibody. Real-time interaction analysis with LigandTracer and surface plasmon resonance were used to evaluate the kinetic binding properties of the generated antibodies to A $\beta$ protofibrils. Different ELISA setups were applied to demonstrate the binding strength of the hexavalent antibody to $A \beta$ aggregates of different sizes. Finally, the ability of the antibodies to protect cells from A $\beta$-induced effects was evaluated by MTT assay.

Results: Using real-time interaction analysis with LigandTracer, the hexavalent design promoted a 40-times enhanced binding with avidity to protofibrils, and most of the added binding strength was attributed to the reduced rate of dissociation. Furthermore, ELISA experiments demonstrated that the hexavalent design also had strong binding to small oligomers, while retaining weak and intermediate binding to monomers and insoluble fibrils. The hexavalent antibody also reduced cell death induced by a mixture of soluble A $\beta$ aggregates.

Conclusion: We provide a new antibody design with increased valency to promote binding avidity to an enhanced range of sizes of $A \beta$ aggregates. This approach should be general and work for any aggregated protein or repetitive target.

Keywords: Multivalent antibodies, Alzheimer's disease, A, Avidity, Oligomers, Protofibrils

*Correspondence: greta.hultqvist@farmbio.uu.se

1 Protein Drug Design, Faculty of Pharmacy, Uppsala University, 75124 Uppsala, Sweden

Full list of author information is available at the end of the article

\section{Background}

Immunotherapy is one of the fastest growing fields in medical research. The success in drug development is partly due to the capability of antibodies to bind their protein targets with high specificity and affinity. Since IgG antibodies have two identical paratopes for the same original author(s) and the source, provide a link to the Creative Commons licence, and indicate if changes were made. The images or other third party material in this article are included in the article's Creative Commons licence, unless indicated otherwise in a credit line to the material. If material is not included in the article's Creative Commons licence and your intended use is not permitted by statutory regulation or exceeds the permitted use, you will need to obtain permission directly from the copyright holder. To view a copy of this licence, visit http://creativecommons.org/licenses/by/4.0/. The Creative Commons Public Domain Dedication waiver (http://creativeco mmons.org/publicdomain/zero/1.0/) applies to the data made available in this article, unless otherwise stated in a credit line to the data. 
epitope, they can bind repetitive targets (e.g. oligomeric $\mathrm{A} \beta$ ) at multiple sites (epitopes). As the number of connected binding sites on one target increases, the rate of dissociation from the target will decrease. This effect is called avidity, which is defined as the unified strength of multiple interactions between an antibody and its target $[1,2]$. The more engaged binding sites, the greater the avidity. For example, IgM antibodies with 10 binding sites can have higher avidity than IgG antibodies, when multiple epitopes on a target are bound simultaneously. It has been shown that antibodies modified into a tetravalent form have higher avidity than bivalent antibodies [3].

Protein aggregation is one of the major pathological hallmarks of several diseases. In Alzheimer's disease (AD), the most common form of neurodegenerative disorders, amyloid beta $(A \beta)$ forms aggregates, which cause neuronal death and lead to impaired memory [4]. Aggregation of the monomeric $A \beta$ proceeds through the formation of intermediate soluble oligomers and protofibrils, and eventually lead to formation of insoluble fibrils and plaques, mainly located in the extracellular space in the brain [5-8]. The latter are easily visible in the postmortem brains from AD patients when labeled with amyloid-binding dyes [9]. However, several studies have shown that the soluble aggregated species (oligomers and protofibrils) are the most toxic forms, since they correlate better with clinical symptoms and have been shown to be the main species responsible for the associated neuronal and synaptic death [7, 10-12].

Passive immunization with anti-A $\beta$ antibodies as a treatment strategy for $\mathrm{AD}$ has been tested in numerous clinical trials $[13,14]$. One of the main challenges with AD immunotherapy is to create an antibody with strong binding to toxic species of $A \beta$, and less binding to the potentially physiologically relevant monomers or insoluble fibrils. The monomers may exert some neuroprotective effects $[15,16]$. It is debated which aggregated species of $A \beta$ are most harmful. Some studies suggest soluble protofibrils [17], while others suggest smaller oligomers $[10,18]$ or dimers $[19,20]$. A general conclusion is that soluble $A \beta$ aggregates are toxic to the cells and hence a relevant target. Smaller oligomers of $A \beta$ are more likely to enter neurons and thereby exert their neurotoxic effects, while larger aggregates like protofibrils might have more indirect toxic effects by for example enhancing neuroinflammation [21].

The binding-selectivity of anti-A $\beta$ antibodies to aggregated species of $A \beta$ over monomers is mainly dependent on avidity. Several antibodies can strongly bind to $A \beta$ aggregates while having a low affinity to monomers via the avidity effect. Examples of such binders include IgM antibodies with 10 binding sites [22, 23], divalent binders [24] and antibodies reaching phase 3 clinical trials like aducanumab [25] and lecanemab (BAN2401) [26, 27]. Increasing the valency of antibodies could potentially increase the interaction time with the targeted antigen if the additional binding sites are able to bind to the target simultaneously. If one paratope is dissociated, there will still be a second paratope in association with the target, which could also increase the chance of the dissociated paratope to bind again to the target [2]. Efforts have been made to increase the valency of antibodies through designing multimeric formats accompanied with a significant decrease in the dissociation rate constants $[28,29]$. However, despite being highly flexible in structure [30], IgG antibodies may not have an avidity effect to small $A \beta$ oligomers [31] due to the spatial distance between the two paratopes of IgG antibodies, which has been previously determined to be around $100 \AA$ [32]. As illustrated in Additional file 1: Fig. S1, the complementarity-determining regions of an IgG4 antibody (PDB ID 5DK3) in its crystal structure are much larger than a 12-mer A $\beta$ (PDB ID 2BEG). However, different subclasses of IgG antibodies have different degrees of flexibility, which should be considered when looking at the interactions of specific antibodies with $\mathrm{A} \beta$ [33].

In this study, we set out to develop new functional multivalent antibodies to enhance antibody avidity to soluble aggregates of $A \beta$, particularly smaller oligomers, while maintaining a weak binding to monomers. For this reason, we have designed and recombinantly produced antibody formats based on an $A \beta$ protofibril antibody [26, 27]. This antibody has strong binding to $A \beta$ protofibrils, moderate binding to insoluble fibrils and weak binding to monomers [34-36]. In this study, we introduced new designs involving engineering additional binding domains (e.g. single-chain fragment variable [scFv]) on the variable domains (binding sites) of the parental antibody, generating tetra- and hexavalent antibodies, and tested their binding to different species of $A \beta$ aggregates and protective effects on cells.

\section{Materials and methods \\ Antibody cloning, expression and purification}

The heavy and light chains of the different antibodies were cloned into two separate pcDNA3.4 vectors (GeneArt, Regensburg, Germany). The recombinant proteins were expressed as described previously [37]. Briefly, Expi293 cells were transfected with $70 \%$ light chain plasmids and $30 \%$ heavy chain plasmids using polyethyleneimine as a transfection agent. Seven to 12 days after transfection, the antibodies were purified using an Äkta start system with protein G columns (Cytiva, Uppsala, Sweden). Acetic acid at $0.7 \%$ was used as an elution buffer, and absorbance at $280 \mathrm{~nm}$ was used to measure the concentrations of purified antibodies. Buffer was 
exchanged to phosphate-buffered saline (PBS) using Zeba desalting columns (Pierce biotech, Rockford, IL) and the antibodies were stored at $-80^{\circ} \mathrm{C}$ until further application.

\section{SDS-PAGE analysis}

SDS-PAGE analysis was performed to confirm the purity and the size of the purified proteins. The antibodies were mixed with LDS sample buffer (Invitrogen, Waltham, MA) and loaded onto $4 \%-12 \%$ Bis-Tris protein gels (Invitrogen, Waltham, MA) without adding reducing agents. The gel was then stained with PAGE blue protein solution (Thermo Scientific, Waltham, MA) using a pre-stained protein marker (LI-COR biosciences, Bad Homburg, Germany) as a molecular weight standard.

\section{Thermal shift assay}

The structural stability of the generated antibodies under thermal stress was evaluated using Tycho nt.6 instrument (NanoTemper Technologies, München, Germany). Equimolar concentrations of the antibodies were heated in a glass capillary where the temperature increased linearly from $35{ }^{\circ} \mathrm{C}$ to $95{ }^{\circ} \mathrm{C}$. Fluorescence intensities at $330 \mathrm{~nm}$ and $350 \mathrm{~nm}$ were recorded, corresponding to tryptophan fluorescence. The assay was performed under three conditions: immediately after thawing the antibodies, following 2-h incubation at $37{ }^{\circ} \mathrm{C}$ and following $72-\mathrm{h}$ incubation at $37^{\circ} \mathrm{C}$.

\section{Labelling of the antibodies with lodine-125}

The recombinant antibodies were labelled with iodine-125 using Chloramine-T as described previously [38]. Briefly, equal amounts of RmAb158 (molecular weight [MW] $150 \mathrm{kDa}$ ), Tetra-RmAb158 (MW $200 \mathrm{kDa}$ ) and Hexa-RmAb158 (MW $250 \mathrm{kDa}$ ) were mixed with the iodine-125 stock solution (Perkin Elmer Inc, Waltham, $\mathrm{MA}$ ) and $1 \mathrm{mg} / \mathrm{ml}$ of Chloramine-T (Sigma Aldrich, Stockholm, Sweden) in PBS. After $90 \mathrm{~s}$, the reaction was stopped by addition of $1 \mathrm{mg} / \mathrm{ml}$ sodium meta-bisulphite (Sigma Aldrich, Stockholm, Sweden). Free and unbound iodine was removed from the labelled antibodies using Zeba mini desalting columns having a MW cut-off of $7 \mathrm{kDa}$ (Pierce biotech, Rockford, IL) and the antibodies were eluted in PBS.

\section{Real-time interaction analysis with LigandTracer}

The binding properties of the antibodies to protofibrils were studied using LigandTracer Grey (Ridgeview Instruments $A B$, Uppsala, Sweden). Briefly, a Petri dish was coated with protofibrils in a defined (target) area and placed on a tilted, rotating support. The area opposite to the target area was defined as the background area. The LigandTracer Grey has a low-energy gamma detector mounted above the upper part of the dish. When the buffer containing radio-labeled antibodies was added to the dish, the inclination ensures that the liquid was mainly in the lower part of the dish outside the detection area. During each full rotation, the decay corrected signals from the target and the background areas were recorded for $30 \mathrm{~s}$ each. Each recording was delayed for $5 \mathrm{~s}$ to allow the buffer to drain from the area being detected. The background signal was subtracted from the target signal to represent specific binding of labeled antibodies to protofibrils. To this end, Petridishes (Corning Inc., Corning, NY) were coated overnight at $4{ }^{\circ} \mathrm{C}$ with $300 \mu \mathrm{l}$ of $500 \mathrm{nM} \mathrm{A} \beta 1-42$ protofibrils, prepared as described previously [31]. The dishes were blocked with $5 \%$ BSA in $1 \times$ PBS for $2 \mathrm{~h}$ at room temperature (RT). To establish the affinity and kinetics of the interaction processes, protofibrils were incubated with two antibody concentrations $(0.3$ and $1 \mathrm{nM}$ in $2 \mathrm{ml}$ of $0.1 \% \mathrm{BSA} / \mathrm{PBS}$ ) for $2.5 \mathrm{~h}$ and $3 \mathrm{~h}$, respectively. After a total incubation of $5.5 \mathrm{~h}$, the dissociation measurement was initiated by removing the antibody-containing solution and adding $3 \mathrm{ml}$ of $0.1 \% \mathrm{BSA} / \mathrm{PBS}$ buffer to the dish. Data evaluation was performed using TraceDrawer software (Ridgeview Instruments $A B$, Uppsala, Sweden). The labelling procedure was performed roughly two hours before starting the first incubation.

\section{Surface plasmon resonance (SPR)}

The binding strength of the recombinant antibodies to $\mathrm{A} \beta$ protofibrils and monomers was further investigated by SPR using Biacore $8 \mathrm{~K}$ instrument (Cytiva, Uppsala, Sweden). Soluble A $\beta 1-42$ protofibrils, prepared as described previously [31], were immobilized by amine coupling (NHS/EDC, GE kit \#BR100633) on a biacore CM5 sensor chip (Cytiva, Uppsala, Sweden). Three-fold dilution series of the recombinant antibodies (ranging from 100 to $1.23 \mathrm{nM}$ ) in PBS-P+ buffer ( $\mathrm{pH} 7.4$ ) (Cytiva, Uppsala, Sweden) were injected using a single cycle kinetic method at a flow rate of $30 \mu \mathrm{l} / \mathrm{min}$ with an association phase of $120 \mathrm{~s}$, followed by a dissociation phase of $7200 \mathrm{~s}$. Injection of buffer was used as a blank control. The binding data were fitted to a 1:1 kinetic model using Biacore Insight Evaluation. The dissociation rate constant was calculated as an average value from 2-5 measurements. Surfaces were regenerated using $3 \mathrm{M} \mathrm{MgCl}_{2}$ between cycles. For binding to monomers, the recombinant antibodies were immobilized on the mentioned chips at a fixed concentration of $1 \mu \mathrm{g} /$ $\mathrm{ml}$. A single cycle kinetic method was used to inject a two-fold dilution series of $\mathrm{A} \beta 1-40$ monomers (ranging from 4000 to $250 \mathrm{nM}$ ) (Bachem, H-1194, Bubendorf, 
Switzerland). The steady-state kinetic model was used for analysis.

\section{Indirect ELISA to demonstrate the avidity of RmAb158 to $A \beta$ protofibrils}

Ninety-six-well half-area plates (Corning Inc., Corning, NY) were coated overnight with $A \beta 1-42$ protofibrils (45 ng/well), prepared as described previously [31], at $4{ }^{\circ} \mathrm{C}$. The plates were blocked the next day with $1 \%$ BSA in PBS for $2 \mathrm{~h}$ at RT, followed by incubation for an additional $2 \mathrm{~h}$ at RT with serial dilutions of RmAb158 (with a starting concentration of $10 \mathrm{nM}$ ) and Fab fragment of RmAb158 (with a starting concentration of $1.25 \mu \mathrm{M}$ ). A polyclonal horse-radish peroxidase (HRP)-conjugated anti-mouse IgG (Sigma-Aldrich, Stockholm, Sweden) was added to the plates and incubated for $1 \mathrm{~h}$ at RT, followed by signal development with K-blue aqueous TMB (Neogen Corp, Lexington, KY). Absorbance was measured at $450 \mathrm{~nm}$ using a FLUOstar Omega microplate reader (BMG Labtech, Ortenberg, Germany).

\section{Generation of cross-linked stabilized $A \beta 1-42$ aggregates and separation through size exclusion chromatography (SEC)}

Synthetic A $\beta 1-42$ (Bachem, Bubendorf, Switzerland) was dissolved in $10 \mathrm{mM} \mathrm{NaOH}$ supplemented with $0.005 \%$ Tween-20 to a final concentration of $100 \mu \mathrm{M}$ and stored in aliquots at $-80{ }^{\circ} \mathrm{C}$. For generation of $\mathrm{A} \beta 1-42$ aggregates, the stock dilution was diluted in $2 \times \mathrm{PBS}$, $\mathrm{pH} 7.4$, to a final concentration of $50 \mu \mathrm{M}$. The $50 \mu \mathrm{M}$ solution was incubated without shaking for $15 \mathrm{~min}$ at $37{ }^{\circ} \mathrm{C}$ to generate $\mathrm{A} \beta 1-42$ aggregates. For stabilization of the metastable A $\beta 1-42$ aggregates, the aggregates were stabilized covalently by the Photo-Induced Cross-linking of Unmodified Proteins (PICUP) method according to a protocol described previously [39]. Mechanistically, PICUP involves photo-oxidation of $\mathrm{Ru} 3+$ in a tris(bipyridyl) $R u$ (II) complex (RuBpy) to $R u 3+$ by irradiation with visible light in the presence of an electron acceptor. Briefly, a typical PICUP reaction was performed in a $50 \mu \mathrm{l}$ reaction volume. To the $50 \mu \mathrm{M}$ A $\beta 1-42$ aggregate solution, $5 \mu \mathrm{l}$ of RuBpy $(2.5 \mathrm{mM}$ dissolved in water) followed by $5 \mu \mathrm{l}$ of ammonium persulfate (APS, $10 \%(w / v)$ in water) was added by pipetting (final concentrations of RuBpy and APS in the reaction mixture were $0.25 \mathrm{mM}$ and $1 \%$, respectively). The solution was quickly irradiated for $5 \mathrm{~s}$ under a general light bulb on the lab bench. Immediately after irradiation, the reaction was quenched by separating the reaction mixture with Zeba spin desalting column $7 \mathrm{k}$ MWCO equilibrated with PBS supplemented with $0.005 \%$ Tween-20 (Thermofisher, Waltham, MA). The PICUP stabilized A $\beta 1-42$ aggregates were heat-treated for $5 \mathrm{~min}$ at $95{ }^{\circ} \mathrm{C}$ prior to separation of A $\beta 1-42$ aggregates by SEC. A Superdex 200 Increase 3.2/300 column (Cytiva, Uppsala, Sweden) was used for size separation of the first batch of A $31-42$ aggregates (Fig. 6) on a Merck Hitachi D-700 HPLC LaChrom system. The second batch of A $\beta 1-42$ aggregates (Additional file 1: Fig. S3a) was separated using a Superdex 75 column (Cytiva, Uppsala, Sweden). The samples were eluted with PBS-Tween, pH 7.4 (50 mM sodium phosphate, $0.15 \mathrm{M}$ $\mathrm{NaCl}, 0.1 \%$ Tween-20, $\mathrm{pH} 7.4$ ) at a flow rate of $0.08 \mathrm{ml} /$ min and data obtained at $214 \mathrm{~nm}$. Before sample injection, the quenched reaction mixture was mixed 1:1 with a $2 \times$ mobile-phase buffer $(100 \mathrm{mM}$ sodium phosphate, $0.3 \mathrm{M} \mathrm{NaCl}, 0.2 \%$ Tween-20, pH 7.4). Fractions were collected every two minutes and stored at $-20{ }^{\circ} \mathrm{C}$ for further analysis. To estimate the size of the separated PICUP A $31-42$ fractions, western blot analysis was performed. Samples were mixed with Laemlli sample buffer containing reducing agent and heated for $5 \mathrm{~min}$ at $95{ }^{\circ} \mathrm{C}$. The denaturated samples were loaded on NuPAGE $12 \%$ BisTris gels (Thermofisher, Waltham, MA), and transferred onto nitrocellulose membranes (Bio-Rad, Hercules, CA). The membranes were blocked with 5\% dry milk (Bio-Rad, Hercules, CA) in TBS-Tween buffer, followed by incubation with rabbit anti-A $\beta 42$ antibody (Bioarctic AB, Stockholm, Sweden).

\section{Sandwich ELISA to check the binding strength to cross-linked $A \beta 1-42$ aggregates and $\alpha$-synuclein aggregates}

The generated antibodies were tested with sandwich ELISA to establish their binding strength to different sizes of the generated cross-linked $A \beta 1-42$ aggregates using the N-terminal specific mouse monoclonal antibody 82E1 (IBL/Tecan Trading AG, Mannedorf, Switzerland) as a positive control. Ninety-six-well half-area plates (Corning Inc., Corning, NY) were coated overnight with $1 \mu \mathrm{g} / \mathrm{ml}$ of the rabbit polyclonal C-terminal-specific A $31-42$ antibody (Invitrogen, Waltham, MA) at $4{ }^{\circ} \mathrm{C}$. On the next day, the plates were blocked with $1 \%$ BSA in PBS for $2 \mathrm{~h}$ at RT and incubated with $250 \mathrm{pM}$ of the generated cross-linked A $\beta 1-42$ aggregates of different sizes for another $2 \mathrm{~h}$. Serial dilutions of the recombinant antibodies were added to the plates and incubated for $2 \mathrm{~h}$ at RT, followed by detection for $1 \mathrm{~h}$ at RT with HRP-conjugated anti-mouse IgG antibody (Sigma Aldrich, Stockholm, Sweden). Signals were developed with K-blue aqueous TMB (Neogen Corp, Lexington, KY) and the absorbance was measured at $450 \mathrm{~nm}$ using a FLUOstar Omega microplate reader (BMG Labtech, Ortenberg, Germany). The wells were washed with ELISA washing buffer (PBS with $0.05 \%$ Tween-20) between each step. All serial dilutions were made with ELISA incubation buffer (PBS with $0.1 \%$ BSA and $0.05 \%$ Tween-20). The absorbance 
of the blank (no addition of recombinant antibodies) was subtracted from the absorbance of the samples. For $\alpha$-synuclein sandwich ELISA, plates were coated overnight with $1 \mu \mathrm{g} / \mathrm{ml}$ of antibody MJFR-14-6-4-2 (Abcam, Cambridge, United Kingdom) at $4{ }^{\circ} \mathrm{C}$. Following block with $1 \%$ BSA in PBS for $2 \mathrm{~h}$ at RT, $\alpha$-synuclein oligomers, prepared as described previously [40], were added at a final concentration of $10 \mathrm{nM}$ and the plates were further incubated for $2 \mathrm{~h}$ at RT. Serial dilutions of the recombinant antibodies (RmAb158, Tetra-RmAb158 and Hexa-RmAb158) were added to the plate and incubated for $2 \mathrm{~h}$ at RT. The $\alpha$-synuclein antibody (clone SynO2, recombinantly produced in the lab) was used as a positive control [41]. The signals were developed and detected as described above.

\section{Inhibition ELISA to discriminate the binding between $A \beta$ monomers, oligomers, protofibrils and fibrils} Inhibition ELISA was performed as described previously [34]. Briefly, 96-well half-area plates (Corning Inc., Corning, NY) were coated overnight with $45 \mathrm{ng} /$ well of $\mathrm{A} \beta 1$ 42 protofibrils at $4{ }^{\circ} \mathrm{C}$ followed by blocking with $1 \%$ BSA in PBS for $2 \mathrm{~h}$ at RT. Serial dilutions of sonicated A $\beta 1$ 42 insoluble fibrils, prepared as described previously [31], large cross-linked $A \beta 1-42$ protofibrils (fraction 1 in SEC chromatogram, Fig. 6), cross-linked A $\beta 1-42$ oligomers (fractions 3 and 4 in SEC chromatogram, Fig. 6) and A $31-40$ monomers (Bachem, Bubendorf, Switzerland) were pre-incubated in a non-binding 96-well plate with HexaRmAb158 at a fixed concentration of 250 pM. After 1.5-h incubation, the mixtures were transferred to the $A \beta$ protofibril-coated plates and further incubated for $15 \mathrm{~min}$ at RT. The plates were washed between the steps and the signal was developed and detected as described above.

\section{Cell culture and MTT assay}

The mouse neuroblastoma Neuro2a cell line was obtained from ATCC (Manassas, VA) and grown in Minimum Essential Medium (Gibco, Carlsbad, CA) supplemented with $10 \%$ fetal bovine serum (Gibco, Carlsbad, CA) at $37{ }^{\circ} \mathrm{C}$ with $5 \% \mathrm{CO}_{2}$. The cells were plated in a 96-well plate (Sarstedt cells +, Numbrecht, Germany) at a density of 5000 cells in $100 \mu$ l complete medium per well. To eliminate the effect of serum, the cells were starved $24 \mathrm{~h}$ prior to the addition of $\mathrm{A} \beta$ /antibody mixtures by changing to a serum-free medium. Cells were then treated with a heterogenous mixture of cross-linked A $\beta 1-42$ aggregates (the sample before being passed through SEC, final concentration $500 \mathrm{nM}$ ) either alone or in combination with the antibodies (final concentration $150 \mathrm{nM}$ ). Cells incubated at standard conditions for $24 \mathrm{~h}$ with PBS were used as a negative control and with
$0.005 \% \mathrm{H}_{2} \mathrm{O}_{2}$ as a positive control. After the mentioned incubation time, the treatment medium was discarded and $50 \mu \mathrm{l} \mathrm{serum}$-free medium plus $50 \mu \mathrm{l}$ MTT reagent (Abcam, Cambridge, United Kingdom) was added in each well and incubated for $3 \mathrm{~h}$ at standard conditions, which lead to the formation of formazin proportional to how many cells that are alive. To solubilize the formazin product, MTT solvent (Abcam, Cambridge, United Kingdom) was added and the plates were incubated in the dark for 15 min while shaking. The absorbance was measured at $590 \mathrm{~nm}$ using a FLUOstar Omega microplate reader (BMG Labtech, Ortenberg, Germany). Data were obtained from two repetitive experiments where five to six replicates were used for each condition and the absorbance of the blank (cell medium only) was subtracted from the absorbance of the samples.

\section{Results}

Generation of recombinant multivalent antibodies

A scFv, consisting of the heavy variable domain attached through a glycine-serine rich linker $[42,43]$ to the light variable domain of RmAb158 (Fig. 1a), was attached to the $\mathrm{N}$-terminal end of the RmAb158 heavy chain to create Tetra-RmAb158 (Fig. 1c), or the N-terminal end of both heavy and light chains of RmAb158 to create HexaRmAb158 (Fig. 1d). The scFv was attached with an inhouse designed linker where prolines were added to the linker to ensure no alpha helices were formed, glycines added to provide flexibility and serines added to give more hydrophilicity [44]. In addition, a dual variable domain (DVD) antibody was designed, where an additional heavy chain variable domain was attached to the $\mathrm{N}$-terminal end of the heavy chain and an additional light chain variable domain was attached to the $\mathrm{N}$-terminal end of the light chain (Fig. 1b).

The four antibodies were expressed in Expi293 cells [37], giving rise to $\sim 20 \mathrm{mg}$ of $\mathrm{RmAb} 158$ or $2-5 \mathrm{mg}$ of DVD, Tetra or Hexa-RmAb158 per liter of transfected cell cultures. After purification with affinity column chromatography, SDS-PAGE analysis showed bands at $150 \mathrm{kDa}$ (RmAb158), $200 \mathrm{kDa}$ (DVD and TetraRmAb158) and $250 \mathrm{kDa}$ (Hexa-RmAb158), confirming the size and purity of the produced recombinant proteins (Fig. 1e).

\section{Structural stability of the recombinant antibodies}

Structural stability of the generated antibodies under thermal stress was evaluated using the Tycho nt.6 system (NanoTemper Technologies, München, Germany). Inflection temperature which refers to the temperature at which the proteins unfold was determined by measuring fluorescence intensities at 350 and $330 \mathrm{~nm}$. RmAb158 yielded an infection temperature of $79{ }^{\circ} \mathrm{C}$ 


\section{a $\quad$ RmAb158 $150 \mathrm{kDa}$}
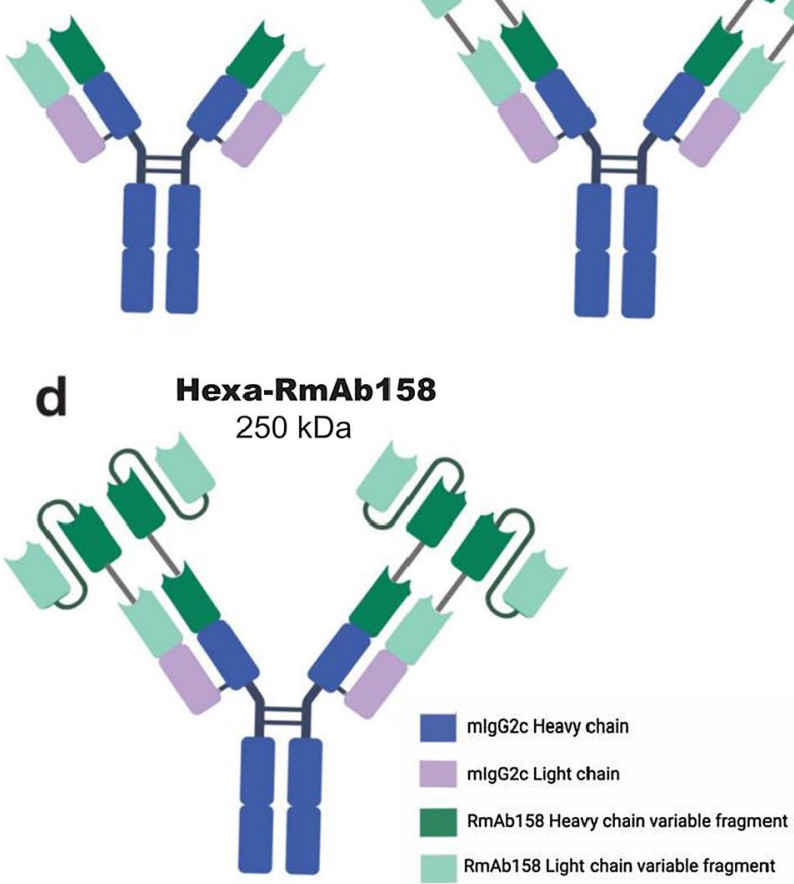

\section{b}

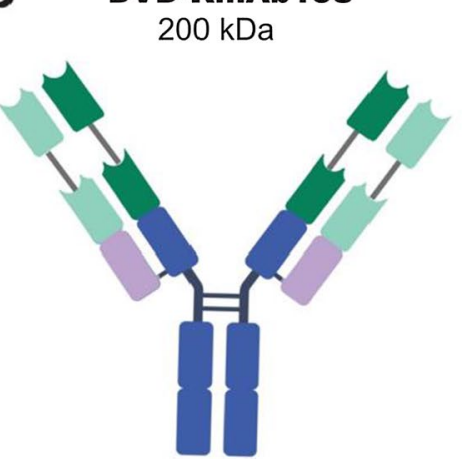

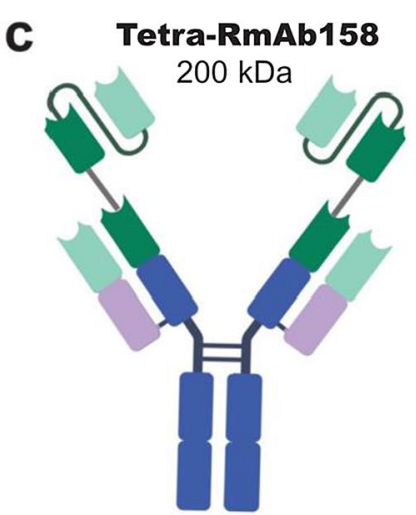

e

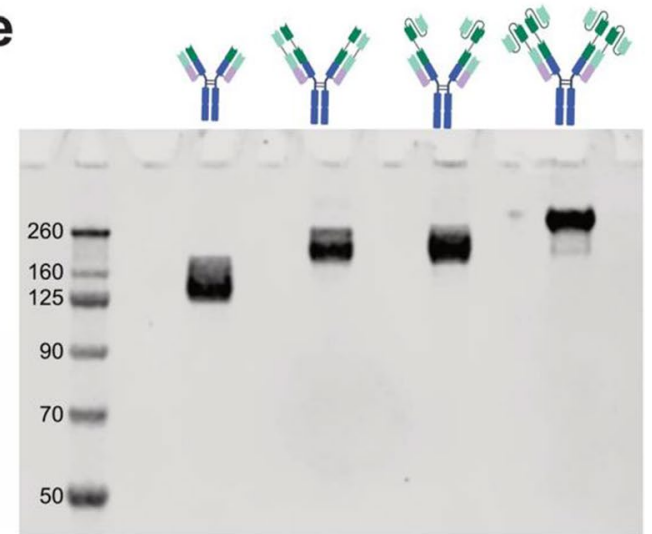

Fig. 1 Design of the different recombinant antibodies. a Schematic picture of RmAb158 antibody. b DVD-RmAb158, where the heavy and light chain variable domains are added to the N-terminal end of Rmab158 heavy and light chains, respectively. c Tetra-RmAb158, where scFvs are added to the N-terminal end of Rmab158 heavy chain only. $\mathbf{d}$ Hexa-RmAb158, where scFvs are added to the N-terminal end of the heavy and light chains of RmAb158. e SDS-PAGE showing a band approximately at 150 kDa for RmAb158, 200 kDa for both DVD-RmAb158 and Tetra-RmAb158, and around $250 \mathrm{kDa}$ for Hexa-RmAb158

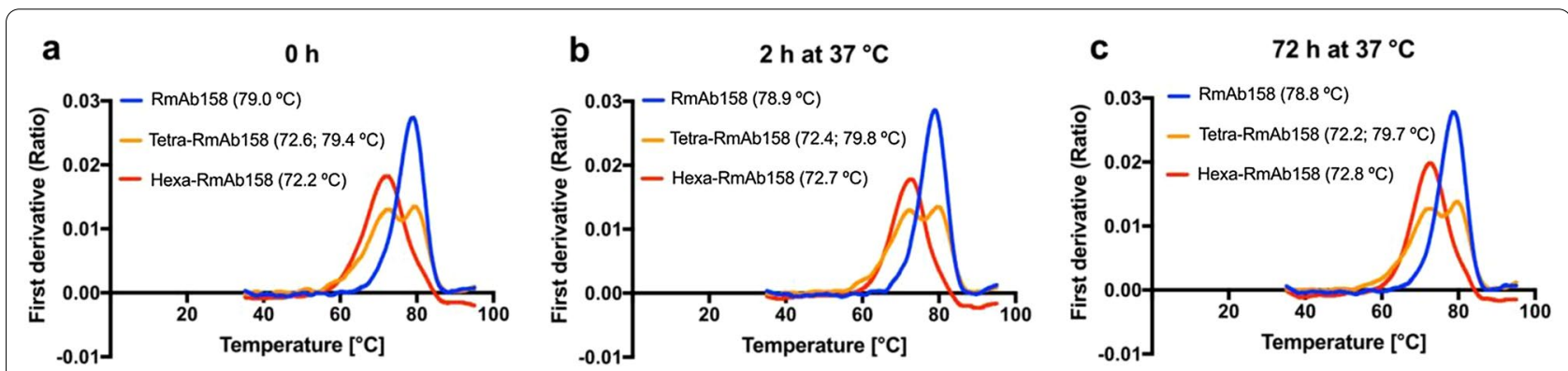

Fig. 2 Structural stability of the recombinant antibodies. Stability of RmAb158, Tetra-RmAb158 and Hexa-RmAb158 under thermal stress evaluated with Tycho nt.6 system (NanoTemper Technologies, München, Germany). Inflection temperature(s) at which the proteins destabilize measured for the three antibodies (final concentration of $1 \mu \mathrm{M}$ ) at $\mathbf{a} 0 \mathrm{~h}, \mathbf{b} 2 \mathrm{~h}$, and $\mathbf{c} 72 \mathrm{~h}$ incubation at $37^{\circ} \mathrm{C}$. Results presented as the ratio of fluorescence intensity at $350 \mathrm{~nm}$ to $330 \mathrm{~nm}$. Changes in fluorescence intensities reflect changes in the proteins'structural stability. Due to the presence of scFv on their N-terminal ends, both Tetra-RmAb158 and Hexa-RmAb158 displayed lower inflection temperatures compared to RmAb158. Inflection temperatures of the three antibodies remained constant after $2 \mathrm{~h}$ and $72 \mathrm{~h}$ incubation at $37^{\circ} \mathrm{C}$, further suggesting structural stability of these antibodies. Results are generated from two-repetitive experiments and average values are shown 
(Fig. 2a). Two inflection temperatures were detected for Tetra-RmAb158 (72.6 ${ }^{\circ} \mathrm{C}$ and $79.4{ }^{\circ} \mathrm{C}$ ) (Fig. 2a). HexaRmAb158 displayed a single inflection temperature of $72.2{ }^{\circ} \mathrm{C}$ (Fig. 2a). The slightly lower inflection temperatures detected for Tetra- and Hexa-RmAb158 antibodies can be attributed to the presence of scFvs on the N-terminal ends of these antibodies, as scFvs are more susceptible to thermal shifts than full IgG antibodies. The inflection temperatures of the three antibodies remained constant after incubation at $37{ }^{\circ} \mathrm{C}$ for $2 \mathrm{~h}$ (Fig. 2b) and $72 \mathrm{~h}$ (Fig. 2c), further suggesting the structural stability of the generated antibodies.

\section{RmAb158 selectivity for $A \beta$ protofibrils is based on avidity}

To demonstrate that RmAb158 utilizes the avidity effect to ensure strong binding to $A \beta$ protofibrils but not monomers, the Fab fragments of the antibody were generated (Fig. 3a). Using an indirect ELISA setup (Fig. 3b), the binding strength to $A \beta 1-42$ protofibrils was examined using the full RmAb158 antibody (MW $150 \mathrm{kDa}$ ), where both binding sites are available, and the Fab fragment of RmAb158 (MW $50 \mathrm{kDa}$ ), where only one binding site is available. A much stronger binding to $A \beta$ protofibrils was observed for RmAb158 as compared to its Fab fragment alone (Fig. 3c). Hence, the strong binding that RmAb158 has to the protofibrils requires the binding of both arms to the same protofibril. This implicates the importance of avidity as a decisive factor in RmAb158's binding selectivity to $A \beta$ aggregates.

\section{Kinetic evaluation of binding of antibodies to $A \beta 1-42$ protofibrils}

The first question on our multivalent antibodies was if they could bind with high avidity to the rather large protofibrils (> $100 \mathrm{kDa}$ in size). The affinity of RmAb158 to $A \beta$ protofibrils has previously been estimated to be approximately $70 \mathrm{pM}[35,45]$, and the affinity of antibody formats with higher valency was expected to be even higher with a lower rate of dissociation. To verify this, the binding strength of the recombinant antibodies to A $\beta 1-42$ protofibrils was determined with realtime interaction analysis using LigandTracer. For these experiments, iodine-125-labeled antibodies were added to dishes coated with $A \beta 1-42$ protofibrils. The association and dissociation rate constants were obtained by monitoring binding during consecutive incubation steps with two concentrations (300 pM and $1 \mathrm{nM}$ ) of the antibodies for $2.5 \mathrm{~h}$ and $3 \mathrm{~h}$ respectively, followed by a phase where the antibodies were removed to measure dissociation rate. Among the three tested antibodies, Hexa-RmAb158 displayed a much slower dissociation with an almost straight dissociation curve (Fig. 4). Kinetic evaluation was done using a 1:1 curve fit. Here, the association event was detected when the first binding site of an individual antibody binds, while for the appearance of signal reduction for the dissociation phase, all binding interactions of the individual antibody need to be dissociated at the same time and hence the antibody not attached at all. Kinetic evaluation of the binding curve for RmAb158 showed an association rate constant $\left(k_{\mathrm{a}}\right)$ of $1.5 \times 10^{5} \mathrm{M}^{-1} \mathrm{~s}^{-1}$, and a dissociation rate constant $\left(k_{\mathrm{d}}\right)$ of $6.5 \times 10^{-6} \mathrm{~s}^{-1}$. The affinity, $K_{\mathrm{D}}$, of the antibody to $\mathrm{A} \beta$ protofibrils was determined to

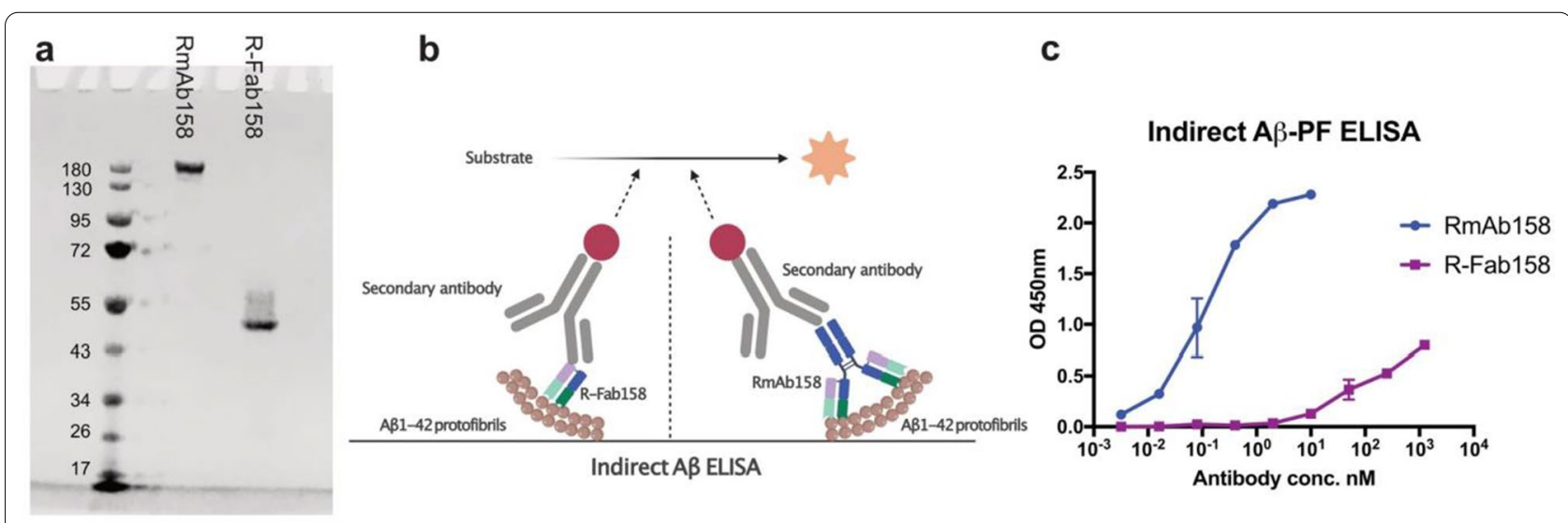

Fig. 3 Studying the avidity of RmAb158 to A protofibrils. a SDS-PAGE showing a single band approximately at $150 \mathrm{kDa}$ for RmAb158 and $50 \mathrm{kDa}$ for its Fab fragment, R-Fab158. b Schematic representation of indirect A ELISA setup where A $31-42$ protofibrils are coated on the well surface, followed by binding of the generated Rmab158 or R-Fab158. c Indirect ELISA displaying the binding curves of RmAb158 and R-Fab158 to A 1-42 protofibrils. Strong binding of RmAb158 to A protofibrils compared to R-Fab158 that demonstrates weak binding. Data are presented as mean $\pm S D, n=2$ 


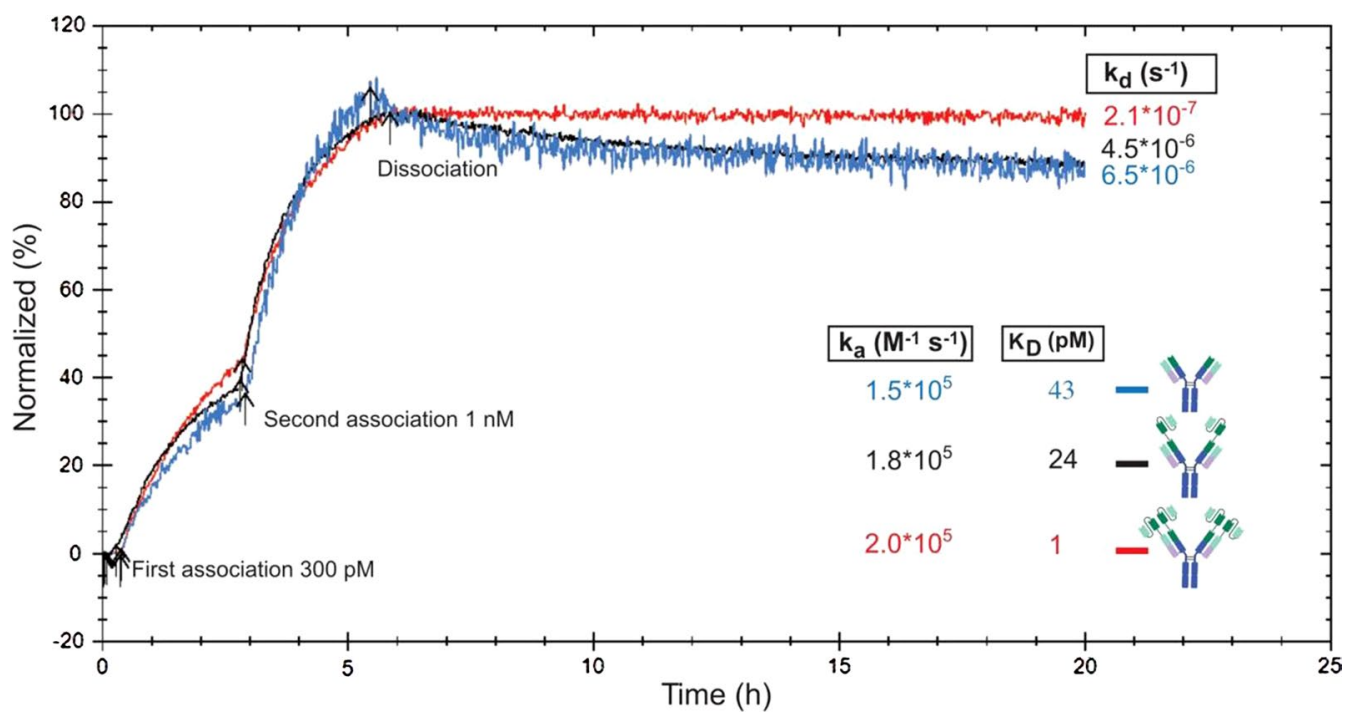

Fig. 4 LigandTracer experiments illustrating the binding strength of the recombinant antibodies to A $1-42$ protofibrils. Detection signal of iodine-125-labelled RmAb158 (blue), Tetra-RmAb158 (black) and Hexa-RmAb158 (red) to Aß1-42 protofibrils, normalized to 100\% corresponding to the maximum binding level, for evaluation of binding behavior and kinetics. Binding curves show association at 300 pM (antibody added at time point $0.5 \mathrm{~h}$ ) and $1 \mathrm{nM}$ (antibody added at time point $3 \mathrm{~h}$ ), and dissociation (when the antibody was removed). Comparison of the affinity $\left(K_{\mathrm{D}}\right)$, association rate constant $\left(k_{\mathrm{a}}\right)$ and dissociation rate constant $\left(k_{\mathrm{d}}\right)$ among the antibodies using one-to-one kinetic model. Results are generated from two repetitive experiments and average affinity constants are shown

be $43 \mathrm{pM}$. Regarding Tetra-RmAb158 binding to $\mathrm{A} \beta$ protofibrils, the antibody displayed an association rate constant of $1.9 \times 10^{5} \mathrm{M}^{-1} \mathrm{~s}^{-1}$ and a dissociation rate constant of $4.5 \times 10^{-6} \mathrm{~s}^{-1}$, with an affinity $K_{\mathrm{D}}$ of $24 \mathrm{pM}$ (Fig. 4). Kinetic evaluation of Hexa-RmAb158 binding to $A \beta$ protofibrils showed an association rate constant of $2.0 \times 10^{5} \mathrm{M}^{-1} \mathrm{~s}^{-1}$. For Hexa-Rmab158, the dissociation rate was very low (almost a straight line, see Fig. 4) and for an accurate estimate of the off-rate and affinity, the fitting was performed in two steps where first the dissociation rate was established followed by fitting the association rate constant while using the dissociation rate from the first step. This resulted in a $k_{\mathrm{d}}$ value of $2.1 \times 10^{-7} \mathrm{~s}^{-1}$, and an affinity $K_{\mathrm{D}}$ of $1 \mathrm{pM}$ (Fig. 4), which were $\sim 40$ times lower than the $k_{\mathrm{d}}$ and $K_{\mathrm{D}}$ values of RmAb158. These results indicate that after incubating the antibodies for several hours with a protofibrilcoated layer, additional scFv units lead to a more stable and higher-affinity binding of the antibodies.

The binding strength of the recombinant antibodies to A $\beta 1-42$ protofibrils was also determined using SPR (Fig. 5a-d). With SPR, it is more difficult to measure the kinetic properties for as long times as with LigandTracer, which is desired in the case of antibodies with slow rate of dissociation. The curve fit to the dissociation phase was good and there was a large difference in the dissociation rate. RmAb158 demonstrated a $k_{\mathrm{d}}$ of $3.86 \times 10^{-3} \mathrm{~s}^{-1}$ (Fig. 5a). DVD-RmAb158 demonstrated an almost 10 times slower dissociation with a $k_{\mathrm{d}}$ value of around $2.64 \times 10^{-4} \mathrm{~s}^{-1}$ (Fig. 5b). Binding of Tetra-RmAb158 and Hexa-RmAb158 to $A \beta 1-42$ protofibrils displayed a $k_{\mathrm{d}}$ value of $2.90 \times 10^{-5} \mathrm{~s}^{-1}$ and $2.56 \times 10^{-5} \mathrm{~s}^{-1}$, respectively. These $k_{\mathrm{d}}$ values were more than 100 times lower than that of RmAb158 (Fig. 5c, d).

The binding strength of the recombinant antibodies to A $\beta 1-40$ monomers was determined with SPR using the steady-state affinity model. The four antibodies displayed weak binding with a $K_{\mathrm{D}}$ value in the range of $2-4 \mu \mathrm{M}$ (Fig. 5e-h).

\section{Evaluation of the binding strength of the multivalent antibodies to different sizes of $A \beta$ aggregates}

The second part of our study aimed at comparing the binding of the different antibody formats to different sizes of soluble $A \beta$ aggregates.

\section{Generation of cross-linked $A \beta$ aggregates of different sizes} Stable A $\beta 1-42$ aggregates of different sizes were generated using the PICUP method followed by fractionation through SEC using a Superdex 200 column (GE Healthcare). The HPLC-SEC chromatogram confirmed the presence of aggregates of different sizes collected in different fractions, with fraction-1 having the largest size and fraction-5 having the lowest MW (Fig. 6). Synthetic monomers of $\mathrm{A} \beta$ had a size of $\sim 4.5 \mathrm{kDa}$. What is defined as $A \beta$ oligomer and protofibril varies 

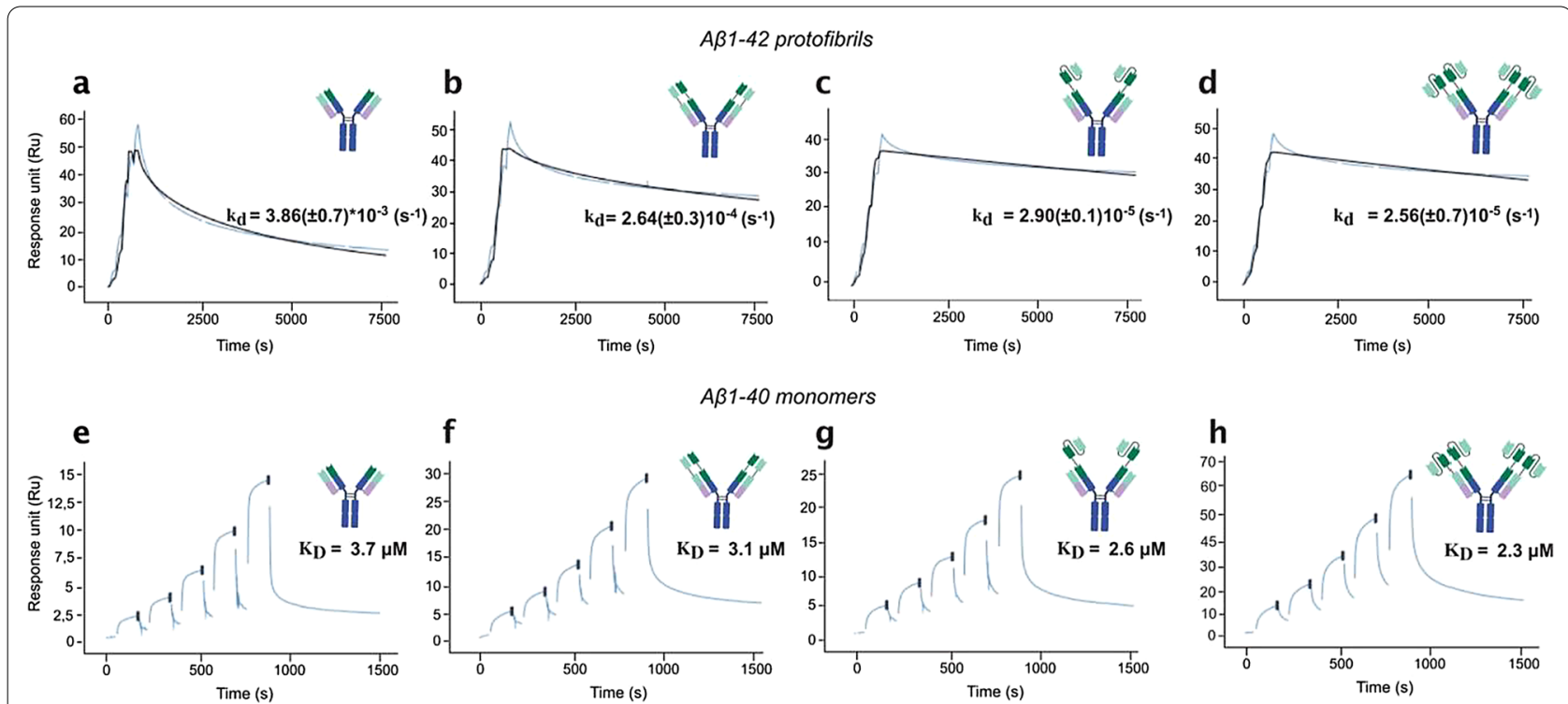

Fig. 5 Surface plasmon resonance (SPR) experiments illustrating the binding strength of the recombinant antibodies to A 3 . a-d Representative sensorgrams for the recombinant antibodies' binding to immobilized A 1-42 protofibrils. Three-fold dilution series of the recombinant antibodies was used to make single cycle kinetic measurements $(1.23,3.7,11.1,33.3$ and $100 \mathrm{nM})$. The dissociation rate constants $\left(k_{\mathrm{d}}\right)$ with standard deviations for the four antibodies were calculated using a one-to-one kinetic model. Lower rate of dissociation from protofibrils is measured in Tetra-RmAb158 (c) and Hexa-RmAb158 (d). e-h Representative sensor grams for A 1-40 monomers binding to immobilized recombinant antibodies. Two-fold dilution series of A 1-40 monomers used $(4000,2000,1000,500$ and $250 \mathrm{nM})$. Lines were fitted using steady state kinetic model. The four antibodies exhibited similar steady-state affinity with $K_{D}$ values in the micromolar range. Results are generated from two to five repetitive experiments

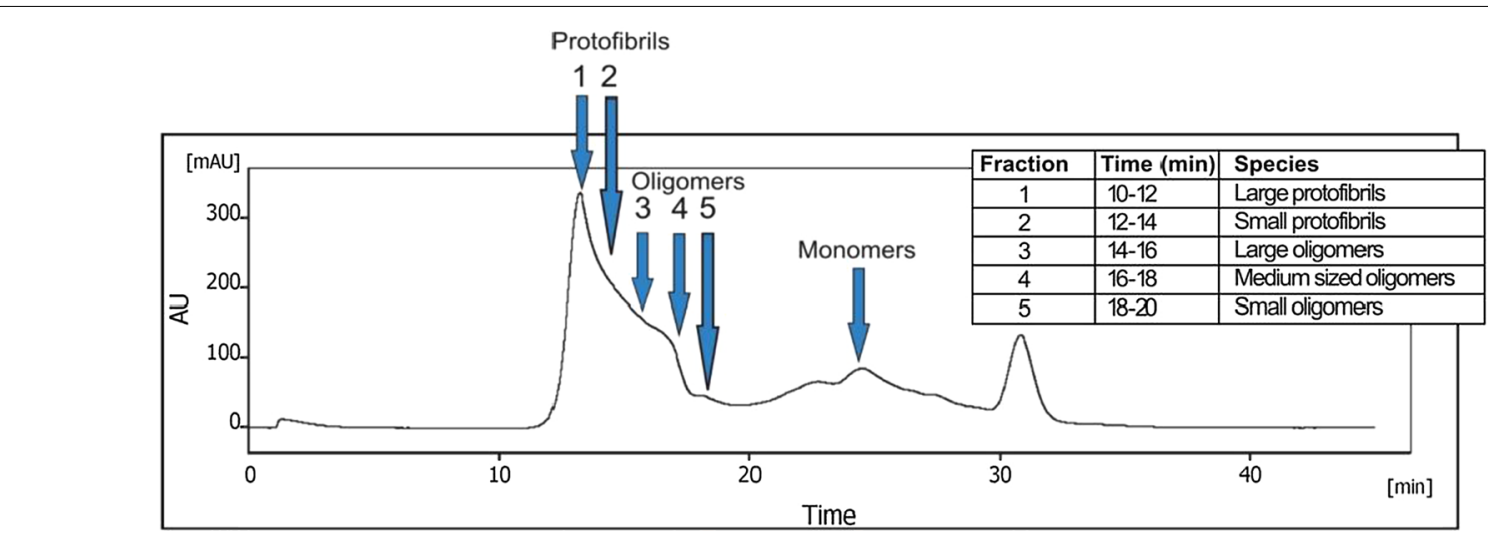

Fig. 6 Generation of cross-linked A $\beta$ aggregates of different sizes. Chromatogram showing the different species of the first batch of cross-linked aggregated A 1-42 separated by SEC using a Superdex200 column. The peak at $~ 30$ min corresponds to retention of salts or degraded amino acids from $A \beta$

among studies. In the current study, $A \beta$ protofibrils were defined as structures with a size of more than $100 \mathrm{kDa}$ that remain soluble after centrifugation at $16,000 \times \mathrm{g}$, and oligomers as soluble aggregates smaller than this. Therefore, fractions 1 and 2 in the SEC chromatogram were defined as large and small protofibrils respectively. Fraction 3 was defined as large oligomers, fraction 4 as medium-sized oligomers and fraction 5 as small oligomers (Fig. 6). 
Evaluation of the binding strength of the recombinant multivalent antibodies to different sizes of cross-linked A 1-42 species with ELISA

Using a sandwich ELISA sparsely coated with an antibody that binds the $C$-terminal end of $A \beta$, we evaluated the binding strength of the multivalent antibodies to $A \beta$ aggregates that vary in size. We used this type of sandwich ELISA with two-hour-long incubations to detect binding to differently sized cross-linked A $\beta 1-42$ aggregates (Fig. 7a). Results showed that all antibody formats showed a similar response to the large cross-linked aggregates (protofibrils, fractions 1 and 2,>100 kDa), regardless of the valency (Fig. $7 \mathrm{~b}, \mathrm{c})$. The method was not sensitive enough to detect differences between very strong binders. However, antibody binding to the smaller aggregates was expected to be substantially reduced and hence differences should be detectable. With such sandwich ELISA setup, we also evaluated the binding strength of the different antibodies to the cross-linked A $\beta 1-42$ fractions 3 and 4 containing the medium-tolarge oligomers of around 60-100 kDa. Results showed that the Hexa-RmAb158 bound stronger than the other recombinant antibodies to fractions 3 and 4 (Fig. $7 d$, e). The Hexa-RmAb158 also displayed some binding to the small cross-linked oligomers at nanomolar concentrations, while the other recombinant antibodies displayed weaker binding (Fig. 7f). The antibody 82E1 has been reported to bind to $A \beta$ of different sizes with similar binding strengths $[46,47]$ and was used as a control here. The DVD-RmAb158 antibody showed a very weak binding strength to almost all the cross-linked $A \beta 1-42$ fractions in this experiment. This antibody format was more prone to aggregate and required very sensitive handling and was therefore not included in all our experiments. The binding strength of each individual antibody to the different fractions of $A \beta$ from the same experiment is illustrated in Additional file 1: Fig. S2.

To estimate the size of $A \beta$ oligomers that can best generate an avidity effect by binding Hexa-RmAb158, we generated another batch of cross-linked A $\beta 1-42$ oligomers (Additional file 1: Fig. S3a-b) where we could collect fractions containing even smaller oligomers than those generated before (Fig. 6).

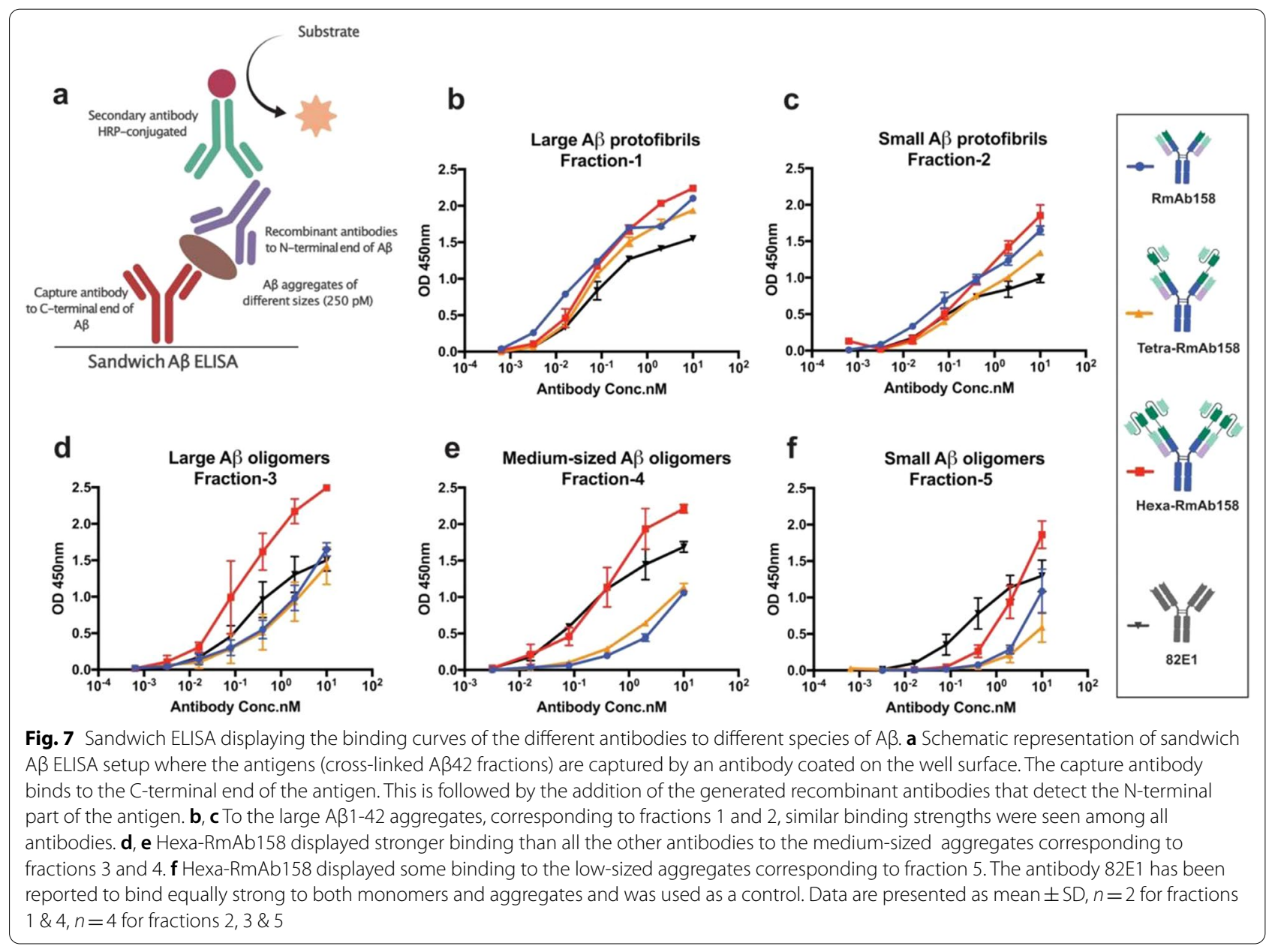


In the same sandwich ELISA setup as described previously, Hexa-RmAb158 displayed the best binding strength to aggregates with a size range of $50-200 \mathrm{kDa}$ (Additional file 1 : Fig. S3c). Nonetheless, the avidity of Hexa-RmAb158 to A $\beta 1-$ 42 decreased in fractions with size $<50 \mathrm{kDa}$ (Additional file 1 : Fig. S3d-f). These results indicate that oligomers of $\sim 50 \mathrm{kDa}$ and above are the species of $A \beta$ that can be best detected with Hexa-RmAb158. As expected from the previous results, the other tested recombinant antibodies also bound weaker to small aggregates in the concentration range used (Additional file 1: Fig. S3d-f).

To investigate if Hexa-RmAb158 bound stronger to oligomers and protofibrils than to insoluble fibrils and monomers, an inhibition ELISA was performed. In this setup, a pre-incubated $A \beta$ aggregate and Hexa-RmAb158 mixture was added to a protofibril-coated ELISA plate (Fig. 8a). The same setup has previously been used to display strong binding of $\mathrm{mAb} 158$ to $\mathrm{A} \beta$ protofibrils, while having intermediate and weak bindings to fibrils and monomers respectively $[31,35,36]$. In this ELISA setup, the ability of the different preincubated $A \beta$ aggregates to inhibit Hexa-RmAb158 binding to the protofibrils bound to the plate should be related to the antibodies' binding strength. The A $\beta$ species used in this ELISA setup were sonicated insoluble $A \beta 1-42$ fibrils prepared as described previously [31], cross-linked A $\beta 1-42$ protofibrils (fraction 1 in the SEC chromatogram, Fig. 6), two smaller sizes of cross-linked A $\beta 1-42$ oligomers (fractions 3 and 4 in the SEC chromatogram, Fig. 6) and $A \beta 1-40$ monomers. Because $A \beta 1-42$ is more prone to aggregate, $A \beta 1-40$ was used to assess monomer binding as it is more stable as a soluble monomer [48]. Hexa-Rmab158 displayed a similar strong binding to the three fractions of cross-linked A $\beta 1-42$ (IC50 of 0.9, 1.0 and $2.0 \mathrm{nM}$, respectively) (Fig. 8b). Importantly, Hexa-RmAb158 exhibited moderate binding strength to sonicated A $\beta 1-42$ fibrils
(IC50 $227 \mathrm{nM}$ ), and weak binding to A $\beta 1-40$ monomers (IC50 834 nM) (Fig. 8b).

\section{Hexa-RmAb158 and related antibodies demonstrate no binding to protein aggregates other than $A \beta$}

To display that Hexa-RmAb158 does not recognize aggregates of other amyloidogenic proteins, a sandwich ELISA was applied (Fig. 9a) detecting $\alpha$-synuclein oligomers, the pathological aggregates in Parkinson's disease. The anti $\alpha$-synuclein antibody (SynO2) was used as a positive control [41]. Hexa-RmAb158, Tetra-RmAb158 and RmAb158 showed no binding to $\alpha$-synuclein aggregates (Fig. 9b).

\section{The hexavalent antibody protects neuronal cells from the toxic effects of $A \beta$ aggregates}

The efficacy of the different antibodies in vitor was studied by investigating their ability to protect mouse neuroblastoma Neuro2a cells from A $\beta$-induced effects on cell metabolism using MTT assay. Since the concentration of the separated fractions of cross-linked A 342 aggregates (Fig. 6) was too low to induce reduction in MTT signal, we performed this experiment with a heterogenous mixture of cross-linked $A \beta 1-42$ aggregates, which also included some proportion of monomers. After over $24 \mathrm{~h}$ of incubation, $500 \mathrm{nM}$ of $\mathrm{A} \beta 1-42$ mixture resulted in a reduction of MTT signal by $53 \%$ (MTT signal $47 \%$ relative to $100 \%$ of PBS-treated cells) (Fig. 10a). The reduced MTT signal was significantly reversed to $~ 65 \%$ by $\operatorname{RmAb} 158(P=0.002)$, to $\sim 70 \%$ by Tetra-RmAb158 $(P=0.003)$, and to $74 \%$ by Hexa-RmAb158 $(P<0.001)$ (Fig. 10a). The control antibody $82 \mathrm{E} 1$ that has a high affinity to the non-toxic monomers as well as the aggregates did not significantly reduce the $A \beta 1-42$ induced toxic effects (Fig. 10a).
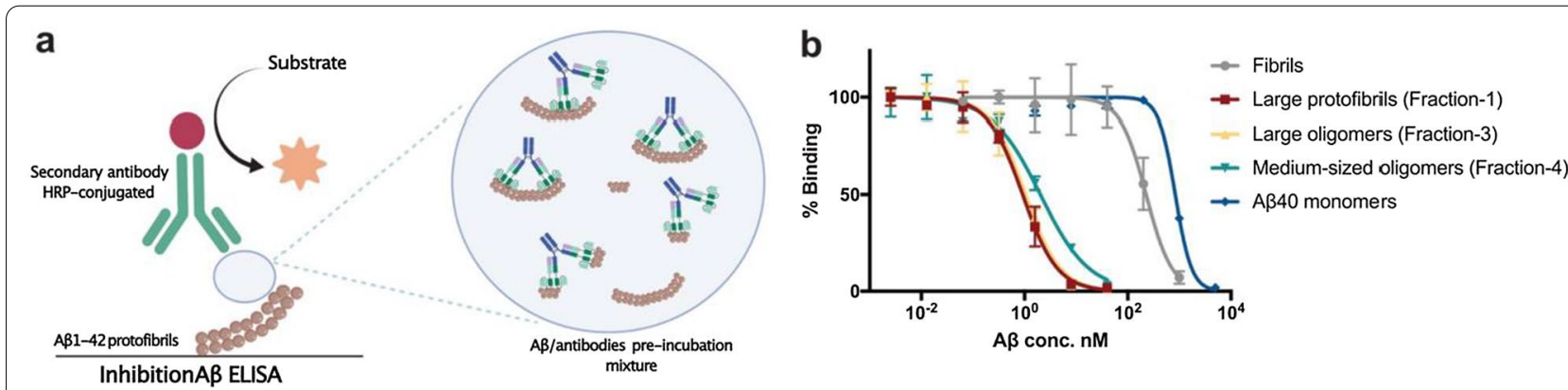

Fig. 8 Inhibition ELISA illustrating the different binding strengths of Hexa-RmAb158 to A 3 . Five different species of A $\beta$ used in this setup: insoluble fibrils, protofibrils in fraction 1, oligomers in fraction 3, oligomers in fraction 4, and $A \beta 40$ monomers. a Schematic representation of inhibition $A \beta$ ELISA, where a pre-incubated AB/antibody mixture is added to a protofibril-coated plate. $\mathbf{b}$ Hexa-RmAb158 displaying a highly selective binding to the protofibrils and both the oligomeric fractions, with moderate binding strength to the fibrils and weak binding to the monomers. The concentrations were log transformed, and the obtained OD values were normalized to 100\% binding, where the highest OD value is defined as $100 \%$ binding, and OD value of zero is defined as $0 \%$ binding. Data are presented as mean $\pm S D, n=2-3$ 

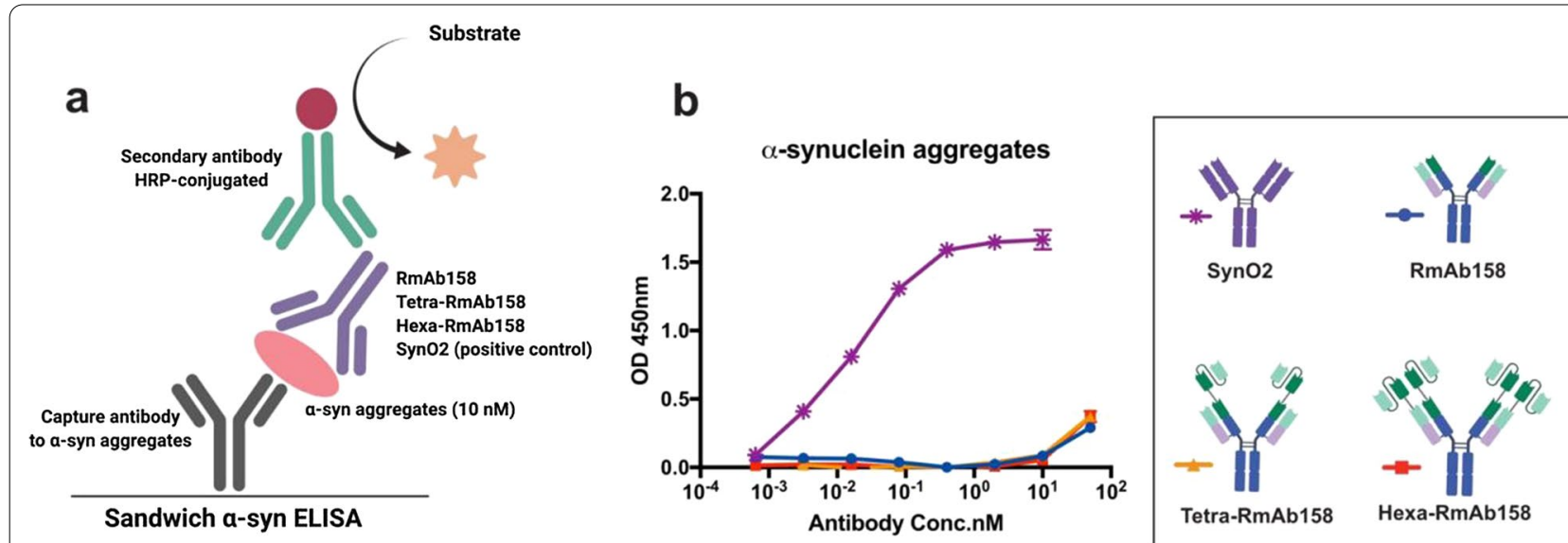

Fig. 9 Sandwich ELISA displaying the binding curves of the different antibodies to a-synuclein aggregates. a Schematic representation of sandwich ELISA setup where the antigen (a-synuclein) was captured by an antibody coated on the well surface. This is followed by the addition of the generated recombinant antibodies. b Hexa-RmAb158, Tetra-RmAb158 and RmAb158 displayed no binding to a-synuclein aggregates. The control antibody SynO2 displayed a strong binding to a-synuclein aggregates. Data are presented as mean $\pm S D, n=3$

\section{Discussion}

Passive immunotherapies using monoclonal antibodies are in ongoing clinical trials for the treatment of AD. Some of these trials have been discontinued due to the lack of efficacy in slowing cognitive impairment [49-51]. A high incidence of adverse events such as amyloidrelated imaging abnormalities with edema (ARIA-E), possibly caused by binding to fibrils in the vessel walls, have been seen in some of the trials [52, 53].

The aim of the current study was to enhance the avidity of monoclonal antibodies through the design of multivalent antibody formats and investigate their binding strength to soluble aggregated species of $A \beta$. These properties are desired because of the high cytotoxicity of the intermediate soluble species of $\mathrm{A} \beta[10,12,54]$. In addition, increasing the avidity will also decrease the rate of dissociation from the soluble $A \beta$ aggregates.

To this end, we have designed, produced and evaluated binding characteristics of multivalent antibodies to different aggregated $A \beta$ species, but also to physiologically abundant monomers. The designs were based on RmAb158, an antibody that has previously been shown to have high binding strength to protofibrils due to avidity $[31,34]$. The humanized version of RmAb158, lecanemab (BAN2401), is currently in a phase 3 clinical trial with 1795 participating patients with early and prodromal $\mathrm{AD}$. In a phase $2 \mathrm{~b}$ trial including 856 patients with $\mathrm{AD}$, lecanemab (BAN2401) demonstrated a remarkable biological activity in lowering $A \beta$ levels in the brain with a good safety profile [55].

We utilized the SPR and LigandTracer techniques to compare the binding of the antibody constructs to protofibrils, since these technologies can establish the affinity and avidity without the necessity of reaching equilibrium in the binding process as with ELISA. For a high avidity binding, as displayed by Hexa-RmAb158 to $A \beta$ protofibrils, $95 \%$ of the equilibrium binding will only, theoretically, be reached after incubation for roughly 17 days when having a concentration similar to the apparent affinity for the interaction. Required incubation times are even longer for lower concentrations. The obtained results from both methods revealed a lower rate of dissociation with Hexa-RmAb158, which showed a slower dissociation from $A \beta$ protofibrils when compared to RmAb158 (Figs. 4, 5). This can be explained by the additional binding domains of Hexa-RmAb158 that provide a higher number of antigen-antibody interaction sites. If one of the paratopes dissociates from its interaction site, there are additional paratopes that are still associated with the target in the case of Hexa-RmAb158. In comparison, Tetra-Rmab158 will have fewer available binding sites, and RmAb158 has only one binding site available. Therefore, a complete dissociation of the hexavalent antibody from its target requires very long times. The dissociation rates measured in the SPR are faster than those from the LigandTracer, which could be due to the longer incubation periods enabling more time for multivalent binding and how the protofibrils are connected to the surface. In LigandTracer, unmodified protofibrils are bound directly to the plate, while in the SPR, the protofibrils are bound to the sensorchip with amine coupling. Since the N-terminal end of $A \beta 1-$ 42 is the epitope for mAb158 [31], it is likely that this is the cause for the weaker binding detected in the SPR, but the relative difference in avidity should still be rather correct. By comparing the measured dissociation process 




and the one estimated by the 1:1 fit in SPR, it can be seen that the actual dissociation is more heterogeneous with a fraction that dissociates more rapidly, leaving more stably bound fraction behind that dissociates more slowly. This heterogeneity might be related to a variation in multivalent binding on the SPR sensorchip, where some antibodies do not manage to bind with all possible binding sites. The advantage of real-time interaction analysis with LigandTracer over SPR is that it allows monitoring of binding to coated layer of $\mathrm{A} \beta$ protofibrils while having longer incubation times to allow reaching of a binding equilibrium.

One of the complications in designing $A \beta$ oligomer antibodies is the cross-reactivity with insoluble fibrils and monomers. Several antibodies have been designed to target $\mathrm{A} \beta$ oligomers, but they have been shown to also bind to fibrillar and monomeric species. Strong binding of antibodies to $A \beta$ fibrils is likely to be associated with an increased risk of ARIA-E, which is a frequently observed adverse event in AD clinical trials 
with monoclonal antibodies [56]. In addition, the monomeric $A \beta$ might play a physiological role and exist in higher amounts than oligomers $[15,57]$. Binding to $A \beta$ monomers in the periphery could also interfere with the ability of the antibodies to reach their intrabrain target. Therefore, antibodies that selectively bind to the oligomers and protofibrils, with low binding to fibrils and monomers, are desired. Here, we showed with inhibition ELISA that the Hexa-RmAb158 has a much stronger binding to the oligomers and protofibrils, which is $\sim 200$ times stronger than its binding to the insoluble fibrils, and 800 times stronger than its binding to the monomers. This has previously been demonstrated with mAb158 as well using similar inhibition ELISA setup [31, 35]. Furthermore, our ELISA experiments displayed no binding of Hexa-RmAb158 and related antibodies to $\alpha$-synuclein aggregates, further confirming the previous report of no binding of the parental mAb158 antibody to protein aggregates other than $A \beta$ [31]. This suggests that binding of HexaRmAb158 is specific to the $N$-terminal of $A \beta$ and not directed towards a structural element common for different amyloidogenic protein aggregates. Being able to strongly bind the soluble oligomeric aggregates of $\mathrm{A} \beta$ could be of therapeutic benefit, since it has been shown that the soluble $A \beta$ aggregates are toxic to neurons and associated with enhanced release of inflammatory cytokines $[58,59]$. This can be explained by their colocalization with several pre- and post-synaptic markers, faster induction of apoptotic changes and activation of the mitochondrial death pathway. In addition, previous research has shown that the small soluble $A \beta 1-42$ aggregates have a higher permeability to cell membranes [21]. In our study, Hexa-RmAb158 was efficient in reducing cell metabolism impairment caused by $A \beta$ of different sizes (Fig. 10a), which could be attributed to the selectivity and low dissociation rates of this antibody to the soluble toxic aggregates of $A \beta$.

Our approach to designing multivalent antibodies could also be applied for other diseases caused by aggregated proteins or repetitive targets. Multivalent antibody designs could provide higher chances for their paratopes to rebind to their targets with decreased dissociation rates, which in turn, could aid in keeping of antibodies in areas around the target. Strong and continuous occupancy of targets could be of particular importance in cancer immunotherapy, where studies have displayed heterogenous and non-tumor specific distribution of antibodies [1]. It is however worth mentioning that enhancing the avidity of antibodies is also dependent on the nature and the surface size of the targeted antigen.

\section{Conclusion}

In conclusion, we have developed a hexavalent antibody that can bind with high avidity to soluble aggregates of $\mathrm{A} \beta$ including small oligomers, while having low binding to the physiological monomers. Due to the decrease in the rate of dissociation, the binding strength of the hexavalent antibody to protofibrils is enhanced by 40 times when measured using real-time interaction analysis with LigandTracer. The binding of the antibody to different $A \beta$ species and the ability to reduce cell death from the toxic effects of $A \beta$ illustrate the potential of such multivalent designs for the generation of diagnostic and therapeutic interventions in the future. Reformatting antibodies to customize the binding profile to targets is possible for many antibodies with extensive use beyond AD.

\section{Abbreviations}

A 3 : Amyloid- $\beta$; AD: Alzheimer's disease; ARIA-E: Amyloid-related imaging abnormalities with edema; DVD: Dual variable domain; PICUP: Photo-induced cross-linking method; scFv: Single chain fragment variable; SPR: Surface plasmon resonance.

\section{Supplementary Information}

The online version contains supplementary material available at https://doi. org/10.1186/s40035-021-00258-x.

Additional file 1. Fig. S1. Ig G antibody and 12-mer A oligomer binding. Fig. S2. Sandwich ELISA displaying the binding properties of each antibody to different cross-linked fractions of A 1-42 generated in Fig. 6. Fig. S3. Sandwich ELISA displaying the binding curves of the different antibodies to another batch of cross-linked $A \beta$ 1-42 fractions.

\section{Acknowledgements}

Schematic illustrations were created with BioRender.com.

\section{Authors' contributions}

G.H designed the project; G.H and F.R designed the constructs; F.R, R.F, K.H and G.H generated the recombinant proteins; F.R, J.B and T.G performed and analyzed radiochemistry and LigandTracer experiments; R.F and K.H performed and analyzed SPR experiments; L.S, L.L and A.M.L generated the cross-linked A $\beta$ fractions; F.R, D.S, G.H designed and performed ELISA experiments; F.R and N.G.M performed structural stability and cell experiments; F.R and G.H wrote the manuscript with valuable inputs from all the co-authors. All authors read and approved the final manuscript.

\section{Funding}

Open access funding provided by Uppsala University. This work was supported by grants from Swedish Research Council, Hedlunds stiftelse, Åke Wibergs stiftelse, Åhlen-stiftelsen, Jeanssons stiftelser, Magnus Bergvalls stiftelse, Vinnova and Alzheimerfonden.

\section{Availability of data and materials}

The datasets used and/or analysed during the current study are available from the corresponding author on reasonable request.

\section{Declarations}

Ethics approval and consent to participate Not applicable. 


\section{Consent for publication \\ Not applicable.}

\section{Competing interests}

R.F; K.H; A.M.L and L.S are employees of BioArctic AB, Stockholm, Sweden. L.L is cofounder of BioArctic AB, Stockholm, Sweden. J.B is CEO of Ridgeview Instruments AB, Uppsala, Sweden. All the other authors declare that they have no competing interests.

\section{Author details}

${ }^{1}$ Protein Drug Design, Faculty of Pharmacy, Uppsala University, 75124 Uppsala, Sweden. ${ }^{2}$ Department of Immunology, Genetics and Pathology, Uppsala University, 75185 Uppsala, Sweden. ${ }^{3}$ Ridgeview Instruments, 75237 Uppsala, Sweden. ${ }^{4}$ BioArctic AB, 11251 Stockholm, Sweden. ${ }^{5}$ Department of Public Health and Caring Sciences, Uppsala University, 75185 Uppsala, Sweden.

\section{Received: 17 March 2021 Accepted: 14 August 2021}

Published online: 28 September 2021

\section{References}

1. Rudnick SI, Adams GP. Affinity and avidity in antibody-based tumor targeting. Cancer Biother Radiopharm. 2009;24:155-61.

2. Vauquelin G, Charlton SJ. Exploring avidity: understanding the potential gains in functional affinity and target residence time of bivalent and heterobivalent ligands. Br J Pharmacol. 168:1771-85.

3. Pack P, MÜller K, Zahn R, Plückthun A. Tetravalent miniantibodies with high avidity assembling in Escherichia colo. J Mol Biol. 1995;246:28-34

4. Reilly JF, Games D, Rydel RE, Freedman S, Schenk D, Young WG, et al. Amyloid deposition in the hippocampus and entorhinal cortex: quantitative analysis of a transgenic mouse model. Proc Natl Acad Sci U S A. 2003;100:4837-42.

5. Esparza TJ, Wildburger NC, Jiang H, Gangolli M, Cairns NJ, Bateman RJ, et al. Soluble amyloid-beta aggregates from human Alzheimer's disease brains. Sci Rep. 2016;6:38187.

6. Murphy MP, LeVine H III. Alzheimer's disease and the amyloid- $\beta$ peptide. J Alzheimers Dis. 2010;19:311-23.

7. Nilsberth C, Westlind-Danielsson A, Eckman CB, Condron MM, Axelman K, Forsell C, et al. The "Arctic" APP mutation (E693G) causes Alzheimer's disease by enhanced A $\beta$ protofibril formation. Nat Neurosci. 2001;4:887-93.

8. Shoji M, Golde TE, Ghiso J, Cheung TT, Estus S, Shaffer LM, et al. Production of the Alzheimer amyloid beta protein by normal proteolytic processing. Science. 1992:258:126-9.

9. Masters CL, Simms G, Weinman NA, Multhaup G, McDonald BL, Beyreuther K. Amyloid plaque core protein in Alzheimer disease and Down syndrome. Proc Natl Acad Sci U S A. 1985;82:4245-9.

10. Lambert MP, Barlow AK, Chromy BA, Edwards C, Freed R, Liosatos $M$, et al. Diffusible, nonfibrillar ligands derived from $A \beta 1-42$ are potent central nervous system neurotoxins. Proc Natl Acad Sci U S A. 1998:95(11):6448-53.

11. Larson ME, Lesné SE. Soluble A $\beta$ oligomer production and toxicity. J Neurochem. 120:125-39.

12. Walsh DM, Klyubin I, Fadeeva JV, Cullen WK, Anwyl R, Wolfe MS, et al. Naturally secreted oligomers of amyloid $\beta$ protein potently inhibit hippocampal long-term potentiation in vivo. Nature. 2002;416:535-9.

13. Piton M, Hirtz C, Desmetz C, Milhau J, Lajoix AD, Bennys $K$, et al. Alzheimer's disease: advances in drug development. J Alzheimers Dis. 2018:65:3-13.

14. Prins ND, Scheltens P. Treating Alzheimer's disease with monoclonal antibodies: current status and outlook for the future. Alzheimers Res Ther 2013:5:56.

15. Giuffrida ML, Caraci F, Pignataro B, Cataldo S, Bona PD, Bruno V, et al. B-Amyloid monomers are neuroprotective. J Neurosci. 2009;29:10582-7.

16. Giuffrida ML, Caraci F, De BP, Pappalardo G, Nicoletti F, Rizzarelli E, et al. The monomer state of beta-amyloid: where the Alzheimer's disease protein meets physiology. Rev Neurosci. 2011;21:83-94.

17. Sehlin $D$, Englund $H$, Simu $B$, Karlsson $M$, Ingelsson M, Nikolajeff $F$, et al. Large aggregates are the major soluble $A \beta$ species in AD brain fractionated with density gradient ultracentrifugation. PLoS One. 2012;7:e32014.
18. Stroud JC, Liu C, Teng PK, Eisenberg D. Toxic fibrillar oligomers of amyloid- $\beta$ have cross- $\beta$ structure. Proc Natl Acad Sci U S A. 2012:109:7717-22.

19. Klyubin I, Betts V, Welzel AT, Blennow K, Zetterberg H, Wallin A, et al. Amyloid beta protein dimer-containing human CSF disrupts synaptic plasticity: prevention by systemic passive immunization. J Neurosci. 2008;28:4231-7.

20. Shankar GM, Li S, Mehta TH, Garcia-Munoz A, Shepardson NE, Smith I, et al. Amyloid $\beta$-protein dimers isolated directly from alzheimer brains impair synaptic plasticity and memory. Nat Med. 2008;14:837-42.

21. De S, Wirthensohn DC, Flagmeier P, Hughes C, Aprile FA, Ruggeri FS, et al. Different soluble aggregates of A 42 can give rise to cellular toxicity through different mechanisms. Nat Commun. 2019;10:1541.

22. Lindhagen-Persson $M$, Brännström $K$, Vestling $M$, Steinitz $M$, Olofsson A. Amyloid- $\beta$ oligomer specificity mediated by the lgM isotype - implications for a specific protective mechanism exerted by endogenous autoantibodies. PLoS One. 2010;5:e13928.

23. Sehlin D, Hedlund M, Lord A, Englund H, Gellerfors P, Paulie S, et al. Heavychain complementarity-determining regions determine conformation selectivity of anti-aß antibodies. Neurodegener Dis. 2011;8:117-23.

24. Brännström K, Lindhagen-Persson M, Gharibyan AL, lakovleva I, Vestling $M$, Sellin ME, et al. A generic method for design of oligomer-specific antibodies. PLoS One. 2014;9:e90857.

25. Arndt JW, Qian F, Smith BA, Quan C, Kilambi KP, Bush MW, et al. Structural and kinetic basis for the selectivity of aducanumab for aggregated forms of amyloid- $\beta$. Sci Rep. 2018;8:1-16.

26. Logovinsky V, Satlin A, Lai R, Swanson C, Kaplow J, Osswald G, et al. Safety and tolerability of BAN2401 - a clinical study in Alzheimer's disease with a protofibril selective $A \beta$ antibody. Alzheimers Res Ther. 2016:8:14.

27. Tucker S, Möller C, Tegerstedt K, Lord A, Laudon H, Sjödahl J, et al. The murine version of BAN2401 (mAb158) selectively reduces amyloid- $\beta$ protofibrils in brain and cerebrospinal fluid of $\mathrm{tg}$-ArcSwe mice. J Alzheimers Dis. 2015:43:575-88.

28. Kortt AA, Dolezal O, Power BE, Hudson PJ. Dimeric and trimeric antibodies: high avidity scFvs for cancer targeting. Biomol Eng. 2001;18:95-108.

29. Zhang J, Tanha J, Hirama T, Khieu NH, To R, Tong-Sevinc H, et al. Pentamerization of single-domain antibodies from phage libraries: a novel strategy for the rapid generation of high-avidity antibody reagents. J Mol Biol. 2004;335:49-56.

30. Tian X, Vestergaard B, Thorolfsson M, Yang Z, Rasmussen HB, Langkilde AE In-depth analysis of subclass-specific conformational preferences of lgG antibodies. IUCrJ. 2015:2:9-18.

31. Englund H, Sehlin D, Johansson A-S, Nilsson LNG, Gellerfors P, Paulie S, et al. Sensitive ELISA detection of amyloid-beta protofibrils in biological samples. J Neurochem. 2007;103:334-45.

32. Sosnick TR, Benjamin DC, Novotny J, Seeger PA, Trewhella J. Distances between the antigen-binding sites of three murine antibody subclasses measured using neutron and X-ray scattering. Biochemistry. 1992:31:1779-86.

33. Jay JW, Bray B, Qi Y, Igbinigie E, Wu H, Li J, et al. lgG antibody 3D structures and dynamics. Antibodies. 2018;7:18.

34. Hultqvist $G$, Syvänen S, Fang XT, Lannfelt L, Sehlin D. Bivalent brain shuttle increases antibody uptake by monovalent binding to the transferrin receptor. Theranostics. 2017;7:308-18.

35. Magnusson K, Sehlin D, Syvänen S, Svedberg MM, Philipson O, Söderberg $L$, et al. Specific uptake of an amyloid- $\beta$ protofibril-binding antibodytracer in AßPP transgenic mouse brain. J Alzheimers Dis. 2013;37:29-40.

36. Sehlin D, Fang XT, Cato L, Antoni G, Lannfelt L, Syvänen S. Antibody-based PET imaging of amyloid beta in mouse models of Alzheimer's disease. Nat Commun. 2016;7:10759.

37. Fang XT, Sehlin D, Lannfelt L, Syvänen S, Hultqvist G. Efficient and inexpensive transient expression of multispecific multivalent antibodies in Expi293 cells. Biol Proced Online. 2017;19:11.

38. Greenwood F, Hunter W, Glover J. The preparation of ${ }^{131}$ I-labelled human growth hormone of high specific radioactivity. Biochem J. 1963;89:114-23.

39. Bitan G, Lomakin A, Teplow DB. Amyloid $\beta$-protein oligomerization prenucleation interactions revealed by photo-induced cross-linking of unmodified proteins. J Biol Chem. 2001;276:35176-84. 
40. Näsström T, Fagerqvist T, Barbu M, Karlsson M, Nikolajeff F, Kasrayan A, et al. The lipid peroxidation products 4-oxo-2-nonenal and 4-hydroxy2-nonenal promote the formation of a-synuclein oligomers with distinct biochemical, morphological, and functional properties. Free Radic Biol Med. 2011;50:428-37.

41. Vaikath NN, Majbour NK, Paleologou KE, Ardah MT, van Dam E, van de Berg WDJ, et al. Generation and characterization of novel conformationspecific monoclonal antibodies for a-synuclein pathology. Neurobiol Dis. 2015:79:81-99.

42. Huston JS, Levinson D, Mudgett-Hunter M, Tai MS, Novotný J, Margolies $\mathrm{MN}$, et al. Protein engineering of antibody binding sites: recovery of specific activity in an anti-digoxin single-chain Fv analogue produced in Escherichia coli. Proc Natl Acad Sci U S A. 1988;85:5879-83.

43. Trinh R, Gurbaxani B, Morrison SL, Seyfzadeh M. Optimization of codon pair use within the (GGGGS)3 linker sequence results in enhanced protein expression. Mol Immunol. 2004;40:717-22.

44. Rofo F, Ugur Yilmaz C, Metzendorf N, Gustavsson T, Beretta C, Erlandsson A, et al. Enhanced neprilysin-mediated degradation of hippocampal $A \beta 42$ with a somatostatin peptide that enters the brain. Theranostics. 2021;11:789-804.

45. Gustavsson T, Syvänen S, O'Callaghan P, Sehlin D. SPECT imaging of distribution and retention of a brain-penetrating bispecific amyloid- $\beta$ antibody in a mouse model of Alzheimer's disease. Transl Neurodegen. 2020;9:37.

46. Eggert S, Midthune B, Cottrell B, Koo EH. Induced dimerization of the amyloid precursor protein leads to decreased amyloid- $\beta$ protein production. J Biol Chem. 2009;284:28943-52.

47. Horikoshi Y, Sakaguchi G, Becker AG, Gray AJ, Duff K, Aisen PS, et al. Development of $A \beta$ terminal end-specific antibodies and sensitive ELISA for $A \beta$ variant. Biochem Biophys Res Commun. 2004;319:733-7.

48. Jarrett JT, Berger EP, Lansbury PT. The carboxy terminus of the beta amyloid protein is critical for the seeding of amyloid formation: implications for the pathogenesis of Alzheimer's disease. Biochemistry. 1993;32:4693-7.

49. van Dyck CH. Anti-amyloid- $\beta$ monoclonal antibodies for Alzheimer's disease: pitfalls and promise. Biol Psychiatry. 2018;83:311-9.
50. Loureiro JC, Pais MV, Stella F, Radanovic M, Teixeira AL, Forlenza OV, et al Passive antiamyloid immunotherapy for Alzheimer's disease. Curr Opin Psychiatry. 2020;33:284-91.

51. Mo J, Li J, Yang Z, Liu Z, Feng J. Efficacy and safety of anti-amyloid- $\beta$ immunotherapy for Alzheimer's disease: a systematic review and network meta-analysis. Ann Clin Transl Neurol. 2017;4:931-42.

52. Arrighi HM, Barakos J, Barkhof F, Tampieri D, Jack C, Melançon D, et al. Amyloid-related imaging abnormalities-haemosiderin (ARIA-H) in patients with Alzheimer's disease treated with bapineuzumab: a historical, prospective secondary analysis. J Neurol Neurosurg Psychiatry. 2016;87:106-12.

53. Chantran Y, Capron J, Alamowitch S, Aucouturier P. Anti-A $\beta$ antibodies and cerebral amyloid angiopathy complications. Front Immunol. 2019;10.

54. Pham E, Crews L, Ubhi K, Hansen L, Adame A, Cartier A, et al. Progressive accumulation of amyloid-beta oligomers in Alzheimer's disease and in amyloid precursor protein transgenic mice is accompanied by selective alterations in synaptic scaffold proteins. FEBS J. 2010;277:3051-67.

55. Tolar M, Abushakra S, Hey JA, Porsteinsson A, Sabbagh M. Aducanumab, gantenerumab, BAN2401, and ALZ-801 — the first wave of amyloidtargeting drugs for Alzheimer's disease with potential for near term approval. Alzheimers Res Ther. 2020;12:95.

56. Sevigny J, Chiao P, Bussière T, Weinreb PH, Williams L, Maier M, et al. The antibody aducanumab reduces $A \beta$ plaques in Alzheimer's disease. Nature. 2016:537:50-6.

57. Yan Y, Wang C. A 340 protects non-toxic $A \beta 42$ monomer from aggregation. J Mol Biol. 2007;369:909-16.

58. Deshpande A, Mina E, Glabe C, Busciglio J. Different conformations of amyloid $\beta$ induce neurotoxicity by distinct mechanisms in human cortical neurons. J Neurosci. 2006;26:6011-8.

59. Wang W, Hou T, Jia L, Wu Q, Quan M, Jia J. Toxic amyloid- $\beta$ oligomers induced self-replication in astrocytes triggering neuronal injury. EBioMedicine. 2019;42:174-87.
Ready to submit your research? Choose BMC and benefit from:

- fast, convenient online submission

- thorough peer review by experienced researchers in your field

- rapid publication on acceptance

- support for research data, including large and complex data types

- gold Open Access which fosters wider collaboration and increased citations

- maximum visibility for your research: over $100 \mathrm{M}$ website views per year

At BMC, research is always in progress.

Learn more biomedcentral.com/submissions 